\title{
CASESTUDY \\ PREDNISOLONE INDUCED DIABETES MELLITUS, HYPERTENSION AND MATURE CATARACT: SERIOUS ADVERSE EVENT AS A CONSEQUENCE OF IMPROPER SELF MEDICATION
}

\author{
*Kamtane Rajesh ${ }^{1}$, Kottur Jaya ${ }^{2}$, Dubey Parikshit ${ }^{2}$, Qamaruddin Mohammed ${ }^{2}$ \\ ${ }^{1}$ MediCiti Institute of Medical Sciences, Hyderabad, Andhra Pradesh, India \\ ${ }^{2}$ Shadan Institute of Medical Sciences, Hyderabad, Andhra Pradesh, India \\ *Corresponding author's email: E-mail: kamtane_rajesh@yahoo.com
}

\begin{abstract}
Prednisolone is a corticosteroid drug useful for the treatment of a wide range of inflammatory and auto-immune conditions. Here, we report a case of 34 years old male patient who presented with complaints of non healing ulcer and diminution of vision in both eyes. On work up, he was found to have denovo diabetes mellitus, hypertension and development of mature cataract in both eyes as a consequence of prolonged use of prednisolone. After admission, his blood sugar level and bloog pressure was brought under control, predisolone was withdrawn gradually with tapering dose and then surgery for cataract was performed. There were no other systemic or ophthalmic diseases revealed by the patient. The main aim of this article is to enlighten the serious consequence of incorrect self medication. Hence, awareness regarding these adverse drug reactions with steroids and proper patient education on complications and side effects of such medications can minimize complications and help in better patient management.

Key-Words: Prednisolone, Cataract, Hypertension, Diabetes Mellitus
\end{abstract}

\section{INTRODUCTION}

Prednisolone is a corticosteroid drug useful for the treatment of a wide range of inflammatory and autoimmune conditions ${ }^{l}$. It is used to treat a number of different conditions, such as inflammation (swelling), severe allergies, adrenal problems, arthritis, asthma, blood or bone marrow problems, eye or vision problems, lupus, skin conditions, kidney problems, ulcerative colitis, and flare-ups of multiple sclerosis. Prolonged use of prednisolone can cause serious side effects such as hypernatremia, hypokalemia, fluid retention, negative nitrogen balance, increased blood urea nitrogen concentration, hypertension, congestive heart failure, glucose intolerance, hyperglycemia, Adrenal suppression, increased patient susceptibility to bacterial, viral, fungal and parasitic infections, increased intraocular pressure, glaucoma, posterior subcapsular cataracts, etc.

\section{CASE HISTORY}

A 34 years old male patient presented with complaint of a non healing ulcer [Figure 1] over his left toe since 1 month secondary to minor injury to his toe in a road traffic accident. It was associated with serous discharge and pricking pain which aggravated on exertion.

He also complained of gradual, painless diminution of vision in both the eyes. With the above said complaints, patient was admitted and examined. He was diagnosed hypertensive and diabetic with blood pressure of $180 / 110 \mathrm{mmHg}$ and General Random Blood Sugar (GRBS) of $264 \mathrm{mg} / \mathrm{dl}$. There was no family history of diabetes mellitus (DM) or hypertension (HTN). Significant laboratory findings were fasting blood sugar level of $141 \mathrm{mg} / \mathrm{dl}$, post

prandial blood sugar level of $203 \mathrm{mg} / \mathrm{dl}$, total WBC count of $10800 / \mathrm{cmm}$ and raised ESR. When examined by ophthalmologist, he was found to have markedly impaired vision in both eyes and was able to appreciate only hand movements and perception of light. $\mathrm{He}$ had developed mature posterior subcapsular cataract in both the eyes [Figure 2].

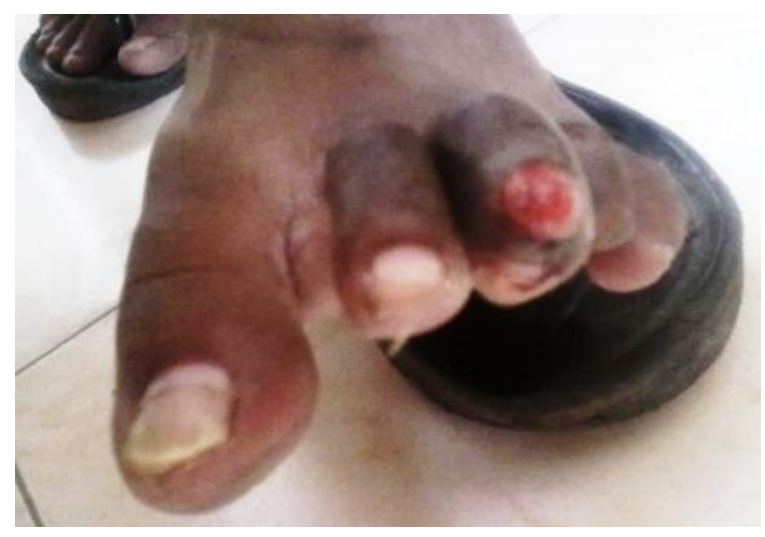

Figure 1: Ulcer over left toe

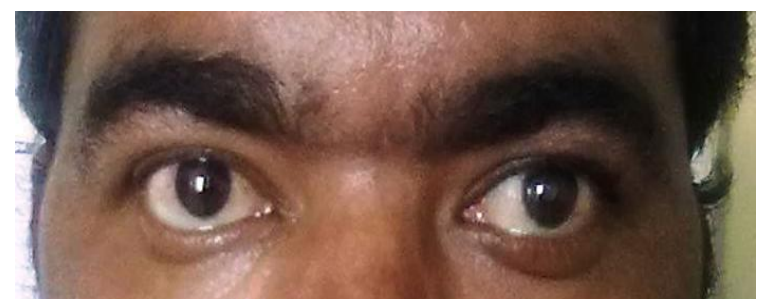

Figure 2: Bilateral Mature Cataract

Drug history revealed that he has been taking prednisolone tablet $20 \mathrm{mg} /$ day for some skin allergy since last 5 years. It was prescribed by a SSN: 2250-1177 CODEN (USA): JDDTAO 


\section{Kamtane et al}

Journal of Drug Delivery \& Therapeutics; 2013, 3(4), 118-119

dermatologist for a short period, but this patient misused it and continued taking it daily as he used to feel better after taking this tablet. After admitting the patient, his blood sugar levels were controlled by using glimeperide, metformin, human actrapid and human mixtard insulins as prescribed by the physician. For HTN control, he was given lasix, telmisartan and amlodipine. $\mathrm{He}$ was given appropriate antibiotic coverage for healing of the ulcer. Prednisolone was withdrawn gradually in tapering dose and this didn't cause recurrence of any dermatologic manifestations for which he continued this drug for such a long period. Proper control over DM and HTN was achieved after a period of approximately one and half month, after which he underwent cataract surgery.

\section{DISCUSSION}

There are various causes of DM, HTN and cataract. Long term use of prednisolone is one of them that can cause all the three disorders. In the present case, it was taken by the patient, continuously for five years in a dose of $20 \mathrm{mg} /$ day for some minor skin allergy. This untoward medical occurrence could

\section{REFERENCES}

1. Czock D, Keller F, Rasche FM, Häussler U. Pharmacokinetics and pharmacodynamics of systemically administered glucocorticoids. Clin Pharmacokinet 2005;44.

2. Aronson JK. Drug therapy. In: Haslett C, Chilvers ER, Boon NA, Colledge NR, Hunter JAA, eds. Davidson's principles and practice of medicine 19th ed. Edinburgh: Elsevier Science, 2002

3. Uppsala monitoring centre. The use of WHO-UMC system for standardized case causality assessment. Available from http://whoumc.org/Graphics/24734.pdf have been avoided, if the patient would have consulted his dermatologist once again. His symptoms could have been managed by antihistamines as and when required. This type of adverse drug reaction can be categorized as Type $\mathrm{C}$ $\mathrm{ADR}^{2}$. There was no family history of DM or HTN. There was no other systemic disease or no other ophthalmological cause that could have contributed to this ADR. To judge the causality, we used WHOUMC case causality assessment scale $^{3}$, which suggested a "probable relationship" between long term prednisolone use and development of DM, HTN and cataract.

\section{CONCLUSION}

Medicines can cause serious harm to human body if misused. This case illustrates clinically important and life threatening adverse effect of prednisolone self medication. Hence, patients should be properly educated regarding side effects and complications of the prescribed medications when they are misused. This can help in minimizing the adverse events.

\section{CONFLICTS OF INTEREST: Nil}

